Volume 18 Number 2 December 2018. p.365-382

https://doi.org/10.30603/au.v18i2.499

\title{
Motif Batik Tradisional Surakarta \\ Tinjauan Makna Filosofis dan Nilai-nilai Islam
}

Siti Nurlaili M \& Ari Hikmawati

IAIN Surakarta

\begin{abstract}
This article discussed the various of traditional Batik motives in Surakarta based on the overview of philosophy meaning and Islamic values. Through the symbolic descriptive interpretation approach, the author tried to find out the meaning of motive in Batik Surakarta. The result of the research shown that at least ten kinds of traditional batik motives in Surakarta. Each of the motives reflected the philosophy meaning and Islamic values. Philosophically, it was found that the meaning in Batik motive is influenced by Hindu teaching, Sangkan Paraning Dumadi. Meanwhile, in Islamic values point of view, traditional motive batik in Surakarta are reflecting the life chronology of human being, from they are in pregnancy phase to the death phase. The Islamic teaching are presented in batik motive covers the theological concept, law concept, and social concept.
\end{abstract}

\begin{abstract}
Abstrak
Batik adalah secarik kain bermotif khas yang dikenal sebagai warisan budaya dunia asal Indonesia. Tulisan ini akan mendiskusikan tentang ragam motif batik tradisional Surakarta dalam tinjauan makna filosofis dan nilai-nilai Islam. Melalui pendekatan interpretaisi simbolik deskriptif penulis akan berusaha untuk menyingkap makna yang terkandung dalam motif batik tersebut. Penelitian menhasilkan temuan bahwa sedikitinya terdapat sepuluh jenis motif batik tradisional Surakarta. Masing-masing motif tersebut selanjutnya menyiratkan makna filosfis dan nilai-nilai Islam yang begitu mendalam. Secara filosofis, ditemukan bahwa makna dalam motof batik yang diproduksi dipengaruhi oleh ajaran Hindu, Sangkan Paraning Dumadi. Adapun ditinjau dari konteks nilai-nilai Islam, motif dalam batik tradisional Surakarta bermakna kronologi kehidupan manusia sejak dalam alam kandungan hingga kembali ke alam barzah. Ajaran Islam yang ditampilkan dalam batik meliputi ajaran aqidah, syariah dan muamalah.
\end{abstract}

\section{Kata kunci: Motif Batik, Makna Filosofis, Nilai Islam}

Author correspondence

Email: ahlaili67.nl@gmail.com

Available online at http://journal.iaingorontalo.ac.id/index.php/au/index 


\section{A. Pendahuluan}

Batik adalah kain yang bergambar hasil kebudayaan masyarakat Indonesia. UNESCO pada tanggal 2 Oktober 2009 menetapkan bahwa batik merupakan warisan budaya dunia yang berasal dari Indonesia. Seiring dengan penetapan pada tanggal tersebut ditetapkan juga hari batik Indonesia. Hal ini selanjutnya berdampak pada tuntutan yang tinggi terhadap kesadaran masyarakat Indonesia termasuk dari kalangan akademisi untuk mempertahankan kelestarian batik sebagai warisan budaya yang tidak ternilai harganya. Selo Soemardjan dan Soelaeman Sumardi merumuskan kebudayaan adalah semua hasil karya, rasa dan cipta masyarakat. ${ }^{1}$ Tidak ada masyarakat yang tidak memiliki kebudayaan, dan juga tidak ada kebudayaan tanpa masyarakat. Kebudayaan termasuk di dalamnya adalah tradisi dengan pewarisan atau penerusan norma - norma, adat - istiadat, kaidah - kaidah, harta - harta. Tradisi bukanlah sesuatu yang tidak dapat diubah. Tradisi dapat dipadukan dengan aneka ragam perbuatan manusia dan diangkat dalam keseluruhannya. Manusia membuat sesuatu dengan tradisi itu, menerima, menolak atau mengubahnya. ${ }^{2}$

Ernst Cassirer menyebut manusia sebagai animal symbolicum. Pemikiran dan tingkah laku yang simbolis merupakan ciri khas manusiawi dan menjadi dasar seluruh kemajuan kebudayaan. ${ }^{3}$ Kebudayaan adalah dunia penuh simbol, tempat dimana manusia dapat membaca dan menemukan ekspresi kehidupan dinamisnya. Simbol mempunyai kedudukan khusus dalam kehidupan relegius manusia. ${ }^{4}$ Orang Jawa adalah manusia yang kaya simbol. Simbol tidak berupa kata - kata, melainkan suatu objek yang menjadi wakil dari sebuah artian. ${ }^{5}$ Sepanjang sejarah manusia Jawa, simbol telah mewarnai tingkah laku, bahasa, ilmu pengetahuan dan religi. Fungsi simbol adalah sebagai media untuk menyampaikan pesan secara halus. Kadang - kadang, simbol berupa sesuatu yang rumit, sehingga hanya manusia yang

\footnotetext{
${ }^{1}$ Wahyu, Wawasan Ilmu Sosial Dasar, Surabaya: Usaha Nasional, 1986. h. 45

${ }^{2}$ Van Peursen, Strategi Kebudayaan, Jakarta-Yogyakarta: Kanisius-BPK Gunung Mulia, 1984. h. 11.

${ }^{3}$ Ernest Cassirer, Manusia dan Kebudayaan, Jakarta: Gramedia , 1987. h. 41

4 Anton Bakker dan Achmad Charris Zubair, Metode Penelitian Filsafat,Yogyakarta:Kanisius, 1990. h. 95.

${ }^{5}$ Budiono Herusatoto, Simbolisme Dalam Budaya Jawa, Yogyakarta: Hanindita Graha Widia, 2003. h. 10.
} 
memiliki pengetahuan lebih (linuwih), yang akan mampu memahami segala bentuk dan tujuannya. Pepatah Jawa Klasik mengatakan wong Jawa iku nggoning semu, sinamun ing samudana, sesadone ingadu manis. Maksudnya, orang Jawa itu tempatnya simbol, segala sesuatunya disamarkan berupa simbol dengan maksud agar tampak indah dan manis.

Batik dalam konsepsi jawa lebih banyak berisikan konsep spiritual yang terwujud dalam bentuk simbol filosofis. Artinya batik sangat erat dengan maknamakna yang simbolis. Motif garuda misalnya, pada batik tradisional bermula dari bentuk burung garuda. Burung ini telah dipakai sebagai lambang Indonesia. Garuda juga dijadikan simbol lambang kendaraan menuju surga, terlihat pada candi-candi Dieng. Motif gurda ini berubah bentuk saat Islam masuk, menjadi bentuk sayap atau lar. ${ }^{6}$

Masyarakat Jawa adalah masyarakat yang sangat menghormati warisan nenek moyangnya, hal ini adalah warisan budaya, warisan itu beragam bentuknya, warisan yang berbentuk religi, kepercayaan atau keyakinan, serta warisan yang berbentuk benda-benda bersejarah. Di antara banyak budaya Jawa, budaya yang paling dominan adalah budaya relijiusnya yang menggunakan sarana tertentu untuk sampai kepada Tuhan. ${ }^{7}$

Di Indonesia, batik sudah ada sejak zaman Majapahit, dan sangat terkenal pada abad XVIII sampae abad XX, dengan batik tulisnya. Model batik cap baru dikenal setelah perang dunia ke $1 .^{8}$ Pada awalnya, motif batik terbentuk dari simbol-simbol yang bermakna, dengan nuansa tradisional Jawa, Hinduisme, Budhisme, dan Islam. Seiring waktu, batik diperkaya dengan nuansa budaya lain, seperti Cina dan Eropa. Ada berbagai macam motif batik dari berbagai daerah di Indonesia, termasuk Surakarta. Surakarta adalah salah satu kota penghasil batik yang produksinya terlaris di Indonesia. Apalagi setelah didukung oleh infrastruktur daerah berupa pasar Klewer yang komoditas utamanya adalah berbagai produk berbahan dasar batik. Ada banyak sekali motif batik yang diproduksi oleh masyarakat di Surakarta. Motif tersebut memiliki makna yang

6 Musman, Astin, dan Ambar B. Arini, Batik Warisan Adiluhung Nusantara. Jakarta:Penerbit GMedia. 2011, h. 37

${ }^{7}$ Bassam Tibi, Islam Kebudayaan dan Perubahan Sosial, Yogyakarta, Tiara Wacana, 1999, h.55

8 Musman, Astin, dan Ambar B. Arini, Batik Warisan Adiluhung Nusantara. h. 37 
berbeda. Banyak orang menjadikan batik sebagai busana wajib saat bekerja, pakaian sehari-hari atau untuk acara-acara yang lebih formal, tetapi tidak semua orang memahami makna yang terdapat pada setiap motif kain batik yang mereka kenakan. Persoalan inilah yang akan didiskusikan dalam tulisan ini, yaitu keanekaragaman motif batik di Surakarta, makna filosofis serta nilai-nilai Islam yang tersirat di dalamnya.

\section{B. Asal-Usul dan Sejarah Batik Surakarta}

Dalam buku Batik Indonesia, Mahakarya Penuh Pesona yang dipersembahkan oleh Paguyuban Pecinta Batik Indonesia disebutkan bahwa puncak kemegahan seni batik Nusantara adalah pada batik yang dikembangkan di Kasunanan Surakarta dan di Kasultanan Yogyakarta. Batik Surakarta dan Yogyakarta dalam istilah Belanda juga disebut dengan "Vorstenlanden". Secara harfiah istilah ini berarti wilayah-wilayah kerajaan yaitu Kasunanan Surakarta dan Kasultanan Yogyakarta.

Secara geografis, batik di luar kawasan kerajaan atau disebut batik pesisiran, yaitu batik yang dihasilkan di luar kawasan Surakarta dan Yogyakarta. Apabila dibandingkan dengan batik daerah pesisir, warna yang digunakan pada batik Surakarta dan Yogyakarta terasa statis karena unsur warnanya sangat terbatas. Umumnya warna yang digunakan hanya untuk melambangkan warna tanah, yaitu coklat, krem, putih, serta warna hitam dan biru. Warna dominan kain batik tradisional Jawa ini pada awalnya dapat kita temukan sebagai berikut:

\section{Warna Cokelat (Dragemsogan)}

Warna cokelat adalah identik dengan warna tanah (lempung) yang subur, dapat membangkitkan rasa kerendahan hati, kesederhanaan dan "membumi", selain kehangatan bagi pemakainya. Dalam pemakainya terutama warna cokelat, sering dipakai pada motif-motif Kawung, Wahyu Tumurun, Semen dan Parang.

\section{Warna Biru Tua (Wulung)}

Warna ini diyakini memberikan efek rasa ketenangan, kepercayaan, kelembutan pekerti, keikhlasan, dan rasa kesetiaan. Kebanyakan warna ini ditemukan pada motif batik tradisional Yogyakarta.

3. Warna Putih 
Warna putih melambangkan arah timur dan memberi kesan suci serta rasa tidak bersalah. Ketentraman hati dan keberanian serta sifat pemaaf. Salah satu contoh penerapan warna dasar putih adalah pada motif Sidoasih.

4. Warna Hitam

Warna-warna yang terdapat dalam motif batik tradisional juga terdapat warna yang kehitam-hitaman. Warna hitam ini melambangkan arah utara. Sesungguhnya warna hitam yang dimaksudkan adalah warna biru yang sangat tua sehingga tampak seperti hitam. Warna hitam ini warna yang sering kali dikonotasikan dengan kematian, ketakutan, dan ketidakbahagiaan. Tetapi sekaligus warna hitam juga melambangkan kekuatan, kemewahan, sensualitas, misteri sekaligus keanggunan.

Pendiri Batik Danar Hadi H. Santosa Doellah mendefinisikan Batik Keraton sebagai batik tradisional, terutama yang tumbuh dan berkembang di KeratonKeraton Jawa. Tata susun ragam hias dan pewarnaanya merupakan paduan yang mengagumkan antara seni, adat, pandangan hidup dan kepribadian lingkungan Keraton. Sebagian motif batik Keraton Surakarta mencerminkan pengaruh Hindu pada zaman Pajajaran dan Majapahit berpengaruh sangat besar dalam seluruh tata kehidupan dan kepercayaan masyarakat Jawa. Pada perkembangannya setelah masukanya ajaran Islam maka terjadi perubahan bentuk pada hiasan yang terkait dengan bentuk makhluk hidup. Pengaruh Hindu tercermin dengan jelas pada motif batik keraton berpola Semen. Meskipun susunan ragam hias batik keraton memiliki aturan yang baku, namun berkat kebebasan dalam menyusun serta memilih ragam hias utama, isen-isen dan ragam hias pengisi, maka batik motif Semen memiliki banyak sekali ragamnya. Sebagian besar warisan budaya klasik Jawa yang masih bertahan hingga kini tetap mengandung unsur Hindu. Suatu akulturasi budaya yang tetap terpelihara di dalam lingkup kehidupan Keraton, sekalipun perubahan dan perkembangan masyarakat di luar Keraton berlangsung dari waktu ke waktu, dan pengaruh Hindu perlahan-lahan semakin surut.

Lahirnya batik motif Surakarta dan motif batik Yogyakarta diakibatkan terjadinya peristiwa politik yang akhirnya berpengaruh pada aspek-aspek budaya yang membedakan antara ciri-ciri Yogyakarta dan Surakarta sebagai sumber atau pusat aktivitas budaya. Peristiwa politik dimaksud adalah Perjanjian Giyanti pada 
tanggal 13 Februari 1755. Perjanjian Giyanti ini memecah Kerajaan Mataram menjadi dua, yaitu wilayah di sebelah timur Kali Opak (melintasi daerah Prambanan sekarang) dikuasai pleh pewaris takhta Mataram (yaitu Sri Susuhunan Pakubuwana III) dan tetap berkedudukan di Surakarta, sementara wilayah di sebelah barat (daerah Mataram yang asli) diserahkan kepada Pangeran Mangkubumi sekaligus ia diangkat menjadi Sultan Hamengkubuwana I yang berkedudukan di Yogyakarta. Perpecahan wilayah tersebut berkelanjutan pada pembagian harta kerajaan yang berupa pusaka, gamelan, kereta tunggangan, dan tandu, yang dibagi menjadi dua bagian. Namun busana Keraton Mataram seutuhnya diboyong oleh Kanjeng Pangeran Mangkubumi ke Yogyakarta. Mengingat sebelumnya terjadinya perpecahan dan ketika Paku Buwana III belum menjadi Raja, Paku Buwana II (ayah Paku Buwana III) pernah berwasiat "mbesuk Manawa pamanmu Mangkubumi hangersakake ageman, paringno" artinya "apabila kelak pamanmu Mangkubumi menghendaki busana, berikan saja”.

Ketika pembatik-pembatik di Keraton Surakarta menghasilkan karya-karya mereka, maka motif-motif batik itu diangkat menjadi hak milik Keraton. Sri Susuhunan Paku Buwana III lalu membuat peraturan tata tertib penggunaan motifmotif batik di kalangan Keraton. Tata tertib penggunaan kain batik ini bertujuan untuk menanamkan kesadaran pada masyarakatnya akan kandungan nilai budaya motif batik. Beberapa motif tertentu bahkan dilarang untuk digunakan di luar keluarga Keraton. Larangan tersebut dikenal dengan istilah Maklumat Solo. Di antaranya isi maklumat itu menyebutkan

“... Apa dene kang arupa jejarit kang kalebu laranganningsun, batik sawat, batik parang lan batik cemukiran kang calacap modang, bangun tulak, lengateleng lan tumpal, apa dene batik cemukiran kang calacap lung-lungan, kang sun wenangake anganggoa pepatihingsun lan sentananingsun, dene kawulaningsun padha wedia".

\section{Yang artinya}

“... ada beberapa jenis kain batik yang menjadi larangan saya, batik sawat, batik parang dan batik cemukiran yang berujung seperti paruh burung podang, bangun tulak lenga teleng serta berwujud tumpal dan juga batik cemukiran yang berbentuk ujung lung (daun tumbuhan yang menjalar di tanah), yang saya izinkan memakai 
adalah Patih dan para Kerabat saya. Sedangkan para kawula tidak diperkenankan".

Dari kebijakan inilah batik motif dan corak Surakarta mulai jadi tatanan berbusana di dalam kehidupan masyarakat Jawa, khususnya di bumi Mataram Surakarta.

Pada masa pemerintahan Paku Buwana IV pembuatan batik semakin berkembang. Setiap golongan didalam keraton dibuatkan motif sendiri-sendiri. Selanjutnya berkembang semakin pesat saat di bawah pemerintahan Paku Buwana X yang memerintah pada periode 1893-1939. Selain nama-nama motif yang telah disebutkan, berikur nama-nama motif batik dan peruntukannya secara protokoer saat dalam Pasowanan di Keraton Surakarta.

\section{Motif-Motif Batik Sesuai Protokoler Keraton Surakarta}

\begin{tabular}{|c|c|}
\hline $\begin{array}{l}\text { Batik Parang Rusak } \\
\text { Motif ini dipakai oleh } \\
\text { bangsawan yang bergelar } \\
\text { Kanjeng Gusti Pangeran Aryo } \\
\text { Adipati (KGPAA), Pangeran } \\
\text { Putra, Pangeran Sentana dan } \\
\text { Sentana dalem yang } \\
\text { berpangkat bupati riya } \\
\text { nginggil yang bergelar } \\
\text { Kanjeng Raden Mas Haryo } \\
\text { (KRMH) }\end{array}$ & $\begin{array}{l}\text { Batik Medhangan } \\
\text { Motif ini dipakai oleh para } \\
\text { Panewu atau Mantri ke bawah } \\
\text { dari golongan Sangkragnyana. }\end{array}$ \\
\hline $\begin{array}{l}\text { Batik Udan Liris } \\
\text { Motif batik ini dipakai oleh } \\
\text { pepatih dalem. }\end{array}$ & $\begin{array}{l}\text { Batik Kumitir } \\
\text { Motif ini digunakan oleh para } \\
\text { Panewu atau Mantri ke bawah } \\
\text { dari golongan kanoman. }\end{array}$ \\
\hline $\begin{array}{l}\text { Batik Rejeng } \\
\text { Motif ini dikenakan para } \\
\text { komandan prajurit (setingkat } \\
\text { Perwira Tinggi) dan duta } \\
\text { keraton. }\end{array}$ & $\begin{array}{l}\text { Batik Tambal Miring } \\
\text { Motif ini dipakai oleh para } \\
\text { Abdidalem yang berpangkat } \\
\text { Panewu atau Mantri dari } \\
\text { golongan Juru Tulis. }\end{array}$ \\
\hline $\begin{array}{l}\text { Batik Tambal Kanoman } \\
\text { Batikan Kampuh atau } \\
\text { Dodotan para Bupati dan } \\
\text { dijadikan seragam Bupati }\end{array}$ & $\begin{array}{l}\text { Batik Jamblang } \\
\text { Motif ini dipakai oleh para } \\
\text { Panewu/ Mantri ke bawah dari } \\
\text { golongan kadipaten Anom. }\end{array}$ \\
\hline
\end{tabular}




\begin{tabular}{|c|c|}
\hline $\begin{array}{l}\text { Anom dan juru tulis kantor di } \\
\text { lingkungan Kabupaten. }\end{array}$ & \\
\hline Batik Semen Latar Putih & Batik Ayam Puser \\
\hline $\begin{array}{l}\text { Motif ini dipakai oleh } \\
\text { Abdidalem berpangkat } \\
\text { Bupati, Bupati Anom dalam } \\
\text { dan luar. }\end{array}$ & $\begin{array}{l}\text { Motif ini dipakai oleh para } \\
\text { Abdidalem yang berpangkat } \\
\text { Panewu/Mantri ke bawah dari } \\
\text { golongan Yogeswara atau } \\
\text { Suranata atau Abdidalem Ulama. }\end{array}$ \\
\hline Batik Padas Gempal & Batik Slobog \\
\hline $\begin{array}{l}\text { Motif ini dipakai para } \\
\text { Abdidalem yang berpangkat } \\
\text { Panewu atau Mantri dari } \\
\text { golongan Sorogeni (prajurit } \\
\text { Sorogeni cirinya berseragam } \\
\text { merah) ke bawah }\end{array}$ & $\begin{array}{l}\text { Motif ini digunakan oleh para } \\
\text { Abdidalem Panewu/Mantri ke } \\
\text { bawah dari golongan niyaga } \\
\text { (penabuh gamelan) }\end{array}$ \\
\hline Batik Wora-Wari Rumpuk & Kain Lurik Perkutut \\
\hline $\begin{array}{l}\text { Motif ini digunakan oleh para } \\
\text { Abdidalem Panewu/Mantri } \\
\text { ke bawah dari golongan } \\
\text { Pangrehpraja atau yang } \\
\text { membawahi wilayah. }\end{array}$ & $\begin{array}{l}\text { Kain Lurik Perkutut merupakan } \\
\text { kain (bukan termasuk batik) yang } \\
\text { dipergunakan sebagai bahan baju } \\
\text { Abdidalem berpangkat Jajar } \\
\text { Priyantaka. }\end{array}$ \\
\hline Batik Krambil Secukil & Kain Sindur \\
\hline $\begin{array}{l}\text { Motif ini digunakan oleh para } \\
\text { Abdidalem Panewu/Mantri } \\
\text { ke bawah, di bawah perintah } \\
\text { Kepatihan. }\end{array}$ & $\begin{array}{l}\text { Kain Sindur merupakan kain } \\
\text { yang dipergunakan Abdidalem } \\
\text { Krisdastawa atau Canthang } \\
\text { balung. }\end{array}$ \\
\hline
\end{tabular}

\section{Ragam Motif Batik Surakarta}

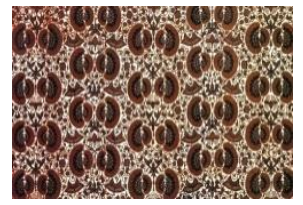

1

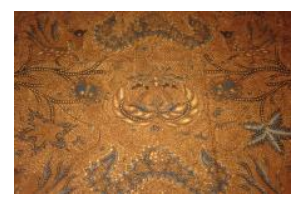

6

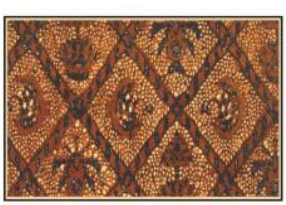

2

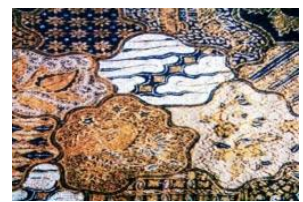

7

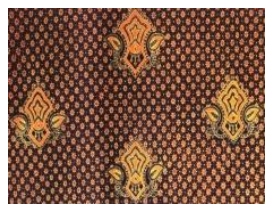

3

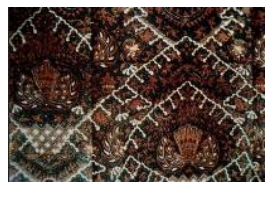

8

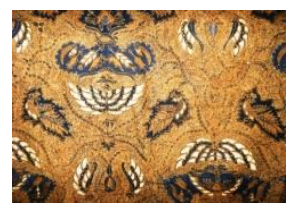

4

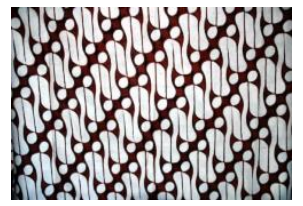

9

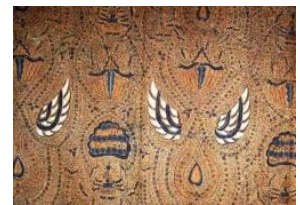

5

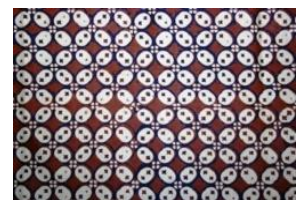

10 
Berdasarkan urutannya, ragam batik pada gambar di atas sesuai dengan urutannya adalah Sawat, Sidomukti, Truntum, Satrio Manah, Semen Rante, Wahyu Tumurun, Sekarjagat, Cuwiri, Parang, dan Kawung. Motif parang membentuk susunan huruf $\mathrm{S}$ yang saling jalin menjalin dari posisi tinggi turun ke posisi lebih rendah dengan membentuk garis-garis diagonal. Motif batik Kawung berpola bulat mirip dengan buah Kawung. Kawung adalah sejenis kelapa atau sebagai buah kolang kaling yang disusun secara rapi geometris. Motif kawung bisa juga diinterpretasikan sebagai bunga teratai atau lotus dengan 4 (empat) lembar daun bunga yang merekah.

Motif Sawat berbentuk dua buah sayap burung garuda atau biasa juga disebut sawat. Dalam motif tersebut terdapat satu sayap yang berukuran besar dan yang lainnya berukuran lebih kecil. Letak sayap ini berhadapan serasi sebagai hiasan. Adapun motif Sidomukti tersusun secara geometrik membentuk bidangbidang persegi. Masing-masing bidang diisi bersama motif pohon hayat, motif kupu-kupu, motif burung dan lain-lainnya. Motif ini berbentuk orrnamen kembang tanjung yang tersebar merata, ada juga yang diberi kombinasi atau diselingi dengan motif lain. Motif tradisional yang satu ini sangat terkenal dan biasanya dipakai pada upacara pernikahan terutama oleh orang tua mempelai.

Motif batik selanjutnya adalah Satrio Manah. Sesuai dengan namanya, motif ini berasosiasi dengan namanya yaitu Satrio yang berarti laki-laki dan manah artinya adalah memanah. Motif Semen Rante dipakai oleh calon mempelai wanita yang sudah bersedia diikat menjadi calon istri. Motif Wahyu Tumurun terdiri 4 unsur yaitu Songkok (mahkota), daun ubi jalar(lung), bunga (kusuma), burung (kukilo). Motif Sekarjagat sesuai dengan namanya adalah motif batik dengan bunga-bunga yang beraneka ragam, bunga yang ada didunia ini. Motif batik Cuwiri menggambarkan keceriaan burung Cuwiri. Motif pokoknya berupa gunung (meru), sayap (lar) dan burung Cuwiri.

\section{Contoh Pemakaian Batik dalam Tradisi Jawa}

\section{Mitoni}

Untuk keperluan upacara Mitoni dipilih tujuh motif batik yang menurut falsafah Jawa memiliki arti dan makna yang positif. Arti dan makna yang dipilih 
juga berhubungan dengan harapan dan keinginan baik kedua orang tua si jabang bayi maupun poro pini sepuh. Diharapkan melalui arti dan makna yang tersirat dalam motif-motif batik yang digunakan, keinginan orang tua dan pini sepuh akan di ijabahi oleh Tuhan Yang Maha Kuasa dan terwujudkan pada di jabang bayi.

Tujuh buah motif batik untuk keperluan upacara mitoni ini adalah; 1). Motif Sido Mulyo yang melambangkan kemulyaan dan kemakmuran, dengan harapan agar bayi yang dilahirkan hidup makmur; 2). Motif Sidoluhur yang melambangkan kemuliaan, maknanya mirip dengan motif sida mulyo, karena luhur artinya sama dengan mulia; 3).Motif Sidoasih yang maknanya agar bayi yang kelak dilahirkan menjadi orang yang dicintai dan dikasihi oleh sesamanya serta mempunyai sifat belas kasih; 4). Motif Sidomukti yang melambangkan kebahagiaan, dengan makna agar bayi yang kelak dilahirkan selalu hidup bahagia;5). Motif Wahyu Tumurun yang melambangkan agar bayi yang akan lahir menjadi orang yang senantiasa mendekatkan diri kepada Tuhan YME dan selalu mandapat petunjuk dan perlindungan dari-Nya; 6). Motif Parang Kusuma. Pada motif Parang Kusumo terkandung suatu makna bahwa suatu kehidupan harus dilandasi dengan perjuangan dan usaha dalam mencapai keharuman lahir dan batin. Hal ini bisa disamakan dengan harumnya suatu bunga (kusuma). Juga dalam falsafat Jawa suatu kehidupan dalam masyarakat yang paling utama harus kita dapatkan adalah keharuman pribadinya, tanpa harus meninggalkan norma-norma dan nilai yang berlaku. Suatu hal yang mudah disampaikan tetapi sulit untuk direalisasikan. Tetapi pada umumnya orang Jawa berharap bisa menempuh suatu kehidupan yang boleh dikatakan sempurna lahir batin yang diperoleh atas jerih payah dari tingkah laku dan pribadi yang baik;7). Semen Rama. Pada motif Semen Romo terdapat suatu harapan agar kedua orang tua si bayi tidak akan berpisahkan sekalipun mendapatkan cobaan seberat apapun. Semen Rama adalah motif batik yang diangkat dari kisah Rama dan Sinta dalam legenda Ramayana.

Semua motif batik tersebut di atas mengandung arti filosofis sendirisendiri. Selain motif batik, juga diperlukan kain lurik, yang biasanya berpola Yuyu sekandhang yang melambangkan harapan agar si anak setelah lahir dikaruniai rizki yang berlimpah. 


\section{Kelahiran dan Tumbuh Kembang Anak}

Batik juga menyertai kelahiran yang digunakan untuk alas, yang disebut kopohan (basahan). Batik ini dipilihkan dari koleksi lama milik nenek si bayi. Ini mengandung arti agar bayi kelak dikaruniai usia panjang seperti neneknya. Pola batik itupun diambilkan yang mempunyai arti filosofi yang baik, sehingga kebaikan itu akan terbawa oleh bayi yang masih suci hingga dewasa nanti. Kain batik kopohan ini selanjutnya disimpan dan dirawat oleh orangtua bayi sebagai pusaka.

Kopohan adalah batik yang digunakan oleh satu keluarga (batih) secara turun-temurun. Kopohan digunakan sesekali saja, sebagai pembungkus bayi saat bayi baru lahir. Kemudian dicuci hanya oleh pihak keluarga. Setelah itu kopohan disimpan di lemari dengan wawancara dari akar lara setu. Kain tersebut baru boleh dikeluarkan dari lemari sebagai suwuk (terapi magis) bagi si bayi di saat sakit.

Saat menanam ari-ari, ayah bayi mengenakan busana Jawa lengkap, kain batik latar hitam dan menggendong kendil berisi ari-ari, dengan kain batik Sidomulyo, Semen Romo, Sidoasih, dan lain-lain, yang disebut kain gendhongan. Itu semua mengandung makna yang senantiasa positif. Bagi kerabat keraton, kain gendhongan berpola Parang Rusak, melambangkan bayi itu masih training luhur tau keturunan bangsawan.

Kain batik juga digunakan dalam upacara memasuki usia dewasa, khusus untuk gadis dalam tahapan pertama kali menstruasi. Setelah siraman mengenakan kain pola Grompol, lambing permohonan kebahagiaan dan kesejahteraan yang nggrompol selalu dikitari dan disukai oleh teman-temannya. Untuk pemuda, batik digunakan saat khitanan dnegan mengenakan batik Parang Pamor yang melambangkan harapan agar setelah dikhitan tumbuh sebagai laki-laki yang cakap dan berbudi luhur, karena telah pecah 'pamor'-nya.

\section{Makna Filosofis dalam Motif Batik Surakarta}

Batik mempunyai makna filosofis berdasarkan pandangan hidup sebagai suatu bentuk kearifan local. Para empu batik menghasilkan rancangan batik melalui proses pengendapan diri, meditasi untuk mendapatkan bisikan-bisikan hati nuraninya, yang diibaratkan guna mendapatkan wahyu. Dengan kata lain 
adalah ide/ kreativitas/ inovasi, tetapi bermakna sangat dalam. Membatik bukan sekedar aktivitas fisik, tetapi mempunyai dimensi ke dalam, mengandung doa atau harapan dan pelajaran.

Keindahan batik mempunyai dua aspek. Pertama yaitu aspek keindahan yang dapat dilihat secara kasat mata atau keindahan visual yang diwujudkan melalui ragam hias batik dan paduan warnanya. Unsur ini dapat dinikmati melalui penglihatan atau pancaindra. Kedua adalah keindahan batik yang lekat dengan makna filosofis atau disebut keindahan jiwa yang diperoleh karena susunan makna lambang ornamen-ornamennya yang membuat gambaran sesuai dengan faham kehidupan. Oleh karena itu, usaha mencipta sebuah motif batik bukan saja melibatkan usaha secara fisik, tetapi juga usaha dari sisi batin.

Ritual dilakukan secara bertahap dari sebelum proses pembuatan batik dimulai. Sebagai langkah awal, biasanya dilakukan wilujengan (selametan), lalu dilanjutkan dengan melakukan puasa, kemudian menyiapkan uba rampe dalam bentuk kembang setaman dan jajanan pasar yang diletakkan di dekat tempat yang akan digunakan untuk membatik. Saat yang dipilih untuk memulai proses pembuatan batik juga dihitung berdasarkan weton atau hari lahir dan pasaran bagi orang yang nantinya akan mengenakan batik tersebut.Sebagaimana diterangkan oleh Wakil Pengageng Sasono Wilopo Keraton Surakarta, Kanjeng Raden Arya Winarno Kusuma, di zaman Pakubuwana III, mori yang akan dijadikan bahan dasar yang akan dibatik harus direndam dulu selama 40 hari 40 malam. Tingkat keseriusan dan konsentrasi penciptaan seperti inilah yang menjadikan motif batik yang dihasilkan diyakini menjadi sebuah karya yang lebih memiliki "roh" serta motifnya mengandung makna filosofi tertentu sebagaimana yang diharapkan dan didoakan pembuatnya.

Motif Parang mengandung makna filosofis terdalam yaitu melambangkan ketajaman rasa dan pikir serta kekuatan dalam menghadapi berbagai masalah dalam kehidupan. Terdapat banyak motif parang, antara lain Parang Kusuma. Parang Kusuma merupakan motif parang yang pada bidang parangnya diberi kusuma (bunga). Bunga ini melambangkan keharuman dan keindahan. Motif ini melambangkan sifat manusia yang selalu senantiasa menjaga dan menjunjung tinggi keharuman atau nama baik diri pribadi, keluarga, bangsa dan Negara. Motif 
Parang juga merupakan simbol harapan masa depan yang baik (mekar). Diharapkan anak yang baru lahir tersebut nantinya akan memiliki sifat seperti makna yang terkandung pada motif Parang Kusuma. Biasanya batik motif Parang ini digunakan pada saat kelahiran dan perawatan ari-ari.

Makna filosofis yang terkandung dalam motif Kawung adalah ajaran Filsafat Jawa "Sangkan Paraning Dumadi" yaitu ajaran tentang proses terjadinya kehidupan manusia, yang sering disebut "sedulurpapat lima pancer" atau "keblat papat lima pancer". Pancer (pusat) di sini adalah manusia. Dalam pandangan hidup atau pandangan filsafat Jawa, ada pendapat bahwa saat bayi lahir (keluar dari rahim ibu), disertai sedulur papat atau 4 saudara, yaitu darah, air ketuban, ariari/plasenta, dan tali pusar; yang selama dalam kandungan diyakini menyertai, menjaga serta melindungi bayi agar selamat lahir ke dunia.

Motif Kawung juga dapat diartikan bahwa manusia sebagai pancer (pusat) dipengaruhi oleh empat sumber tenaga alam yang terpancar dari empat arah mata angin, yaitu timur, selatan, barat, dan utara. Timur adalah tempat terbitnya matahari sebagai awal kehidupan di pagi hari, simbol sumber energy. Selatan adalah arah terik matahari yang dapat dihubungkan dengan katulistiwa atau puncak segalanya. Barat adalah arah matahari terbenam merupakan arah menurunnya keberuntungan, namun di saat itu manusia telah menemukan ketenangan dan kematangan dalam hidupnya. Utara, merupakan arah kematian, di mana manusia berpulang kembali kepada Sang Pencipta.

Kawung juga diasosiasikan sebagai biji buah aren (enau) atau kolang-kaling yang berbentuk elips. Pohon enau merupakan tanaman serbaguna: daunnya dapat digunakan sebagai atap rumah, nira (air sari bunga) untuk membuat gula, buahnya (kolang-kaling) bisa dimakan atau sebagai bahan minuman, ijuk yang ada di batang pohonnya bisa dibuat tali atau alat seperti sapu. Motif batik kawung kadang digunakan pada ritual mitoni untuk perempuan yang sedang hamil. Pemakaian tersebut mengandung harapan agar sang bayi akan banyak berguna pula bagi sesama dan lingkungannya. Kawung juga digunakan pada saat upacara Ruwatan agar diperoleh kehidupan yang mapan lahir maupun batin. Kawung bisa juga digunakan juga sebagai penutup jenazah (lurub) dengan harapan agar sang jenazah dapat lancar kembali kepada alam keabadian (kelanggengan). Kawung 
dimaksudkan sebagai "bali nang alam suwung" yaitu kembali kepada alam hampa keduniawian (alam baka).

Kain batik motif Sawat Manak merupakan simbol (lambang) harapan bahwa relasi antar anak dan orangtuanya bisa berjalan seiring, sejalan, rukun dan damai. Diharapkan demikian yang terjadi pada hubungan anak dan orang tuanya, sehingga motif ini digunakan sebagai kain untuk menggendong. . Motif batik ini mengandung makna filosofis melambangkan harapan agar bayi akan menjadi seorang yang mampu mencapai "kamukten" atau berhasil mencapai kebahagiaan lahir batin, terhormat di lingkungan masyarakat. Kain batik motif Sidaluhur ini melambangkan harapan agar sang bayi menjadi orang yang luhur, baik dalam kedudukan atau jabatan di masyarakat maupun dalam budi pekerti dan perilaku sehingga pantas menjadi teladan

Motif batik truntum digunakan juga sebagai kain gendong bayi (mbanmban) dengan harapan hidup sang anak nantinya diwarnai rasa cinta kasih pada sesama. Manusia lahir karena adanya cinta. Karena itu diharapkan hidupnya juga dipenuhi cinta kepada sesama, alam lingkungan, makhluk ciptaan Tuhan, dan memelihara cinta untuk kebaikan. Motif batik satrio manah adalah motif yang biasanya dipakai pada saat lamaran atau peningsetan oleh pihak calon pengantin laki-laki. Makna filosofis dan makna simbol dari batik Satria Manah adalah menggambarkan memanah sang pujaan hati yaitu wanita yang dipilih sebagai calon istri. Diharapkan nantinya sang istri akan "bekti" dan menjadi pendamping hidup yang baik sebagai garwa (sigaraning nyara = belahan jiwa). Sedangkan calon pengantin putri mengenakan batik motif Semen Rante. Batik Semen Rante dikenakan calon pengantin putri mengibaratkan bahwa sang gadis atau wanita yang dipanah sudah bersedia dirantai atau diikat sebagai istri pasangan hidup atau garwa.

Motif Wahyu Tumurun mempunyai makna harapan atau permohonan mendapatkan wahyu (anugerah), bimbingan dan petunjuk dari Tuhan YME, jauh dari hambatan dan rintangan. Dengan demikian diharapkan sang anak bisa tumbuh dan berkembang sesuai harapan sebagai anggota masyarakat. Motif batik Wahyu Tumurun ini digunakan digunakan saat upacara siraman sebagai harapan mendapatkan anugerah untuk menjalankan hidup sehingga jauh dari godaan dan 
rintangan. . Makna filosofis yang terkandung dalam motif Sekar Jagad adalah melambangkan ungkapan cinta kasih dan memiliki unsur-unsur memelihara perdamaian. Motif batik ini digunakan pada upacara pernikahan. Diharapkan sang mempelai dengan memakai motif Sekar Jagad atau bunga dunia akan hidup penuh dengan keharmonisan baik dengan sesama maupun dengan lingkungannya. Makna filosofis yang terkandung dalam motif batik Cuwiri adalah diharapkan hidup ini mendapatkan kemakmuran dan kebaikan serta dihormati masyarakat luas. Motif batik Cuwiri biasanya dipergunakan saat upacara mitoni atau tujuh bulanan.

\section{E. Batik sebagai Representasi Nilai Islam}

Praktik budaya lokal khususnya motif batik tradisional Surakarta bisa menjadi basis implementasi ajaran-ajaran Islam. Kedudukan Al Quran berperan sebagai giding line bagi proses enkulturasi terhadap adat istiadat yang berjalan. Dengan demikian, masyarakat dapat menjalankan nilai-nilai Islam tanpa harus kehilangan tradisi budaya setempat.Di sinilah letak keuntetikan Islam, yaitu ketika masyarakat menjalankan seruan agamanya dalam konteks kebudayaan yang dimiliki. $^{9}$

Budaya batik menjadi sarana untuk melakukan enkulturasi nilai-nilai Islam ke dalam kebudayaan masyarakat Surakarta.Pranata sosial yang mengharuskan penggunaan motif batik tradisional tertentu yang disesuaikan dengan acara upacara adat, melambangkan adanya makna symbol nilai Islam yang ada.Pranatapranata tersebut tidak luput dari hasil dialektika antara adat istiadat yang berkembang dengan ajaran Islam.

Sebagaimana dalam hadits Rasulullah yang mengajarkan larangan untuk menggambarkan sesuatu yang bernyawa seperti hewan dan manusia, maka dalam motif batik tidak dibuat utuh bentuknya, tapi hanya potongan dari bagian hewan. Seperti motif semen yang berarti :semai bersemi" adalah motif yang paling banyak digunakan. Ornamen dasarnya adalah ragam hias yang berhubungan dengan daratan (tumbuh-tumbuhan dan binatang berkaki empat), udara (burung dan

\footnotetext{
${ }^{9}$ Ali Sodiqin, Antropologi AL-Quran Model Dialektika Wahyu \& Budaya,Yogjakarta : Ar-Ruzz Media, 2008. h.209
} 
awan), serta air atau laut (ular, ikan, dan katak), dan Semen gurdo yang hanya digambar sayapnya.

Proses pembuatan batik juga menggunakan ritual puasa dan pembacaan doa-doa secara Islam sebagaimana dilakukan Sultan yang merupakan seorang Panatagama. Dengan ritual tersebut, diharapkan proses pembuatan batik akan berlangsung lancar, syukur bisa menghasilkan batik bernilai tinggi yang bisa memancarkan aura bagi pemakainya (pecah pamore). Terlebih bila batik yang dibuat itu akan dipakai oleh sinuwun atau keluarga keraton yang lain.

Dalam Islam, aqidah atau kepercayaan merupakan keimanan yang menjadi landasan dalam beragama. Suatu keyakinan yang dilandaskan kepada Al Qur'an dan Hadits. Keimanan menjadi landasan seseorang dalam melakukan tindakan dalam kehidupan sehari-sehari. Seiring dengan ritual puasa dan doa dalam aktifitas membatik merupakan bentuk aktualisasi diri seseorang dalam menyandarkan segala perbuatan dengan dilandasi dengan keimanan. Tingkat keseriusan dan konsentrasi penciptaan seperti inilah yang menjadikan motif batik yang dihasilkan diyakini menjadi sebuah karya yang lebih memiliki "roh" serta motifnya mengandung makna tujuan tertentu sebagaimana yang diharapkan dan didoakan pembuatnya.

Ritual yang dilakukan dalam menciptakan motif batik merupakan upaya memperoleh petunjuk kepada Allah. Dalam Islam, usaha memohon petunjuk dalam menghasilkan karya disebut dengan Ilmu Mauhibah. Ilmu Mauhibah menurut asSuyuthi adalah sebuah ilmu pengetahuan yang di-ilham-kan Allah kepada manusia yang dengan sepenuh hati mengamalkan segala yang ia peroleh dan berbuat menurut pemahaman yang ia capai ('amila bima 'alima). Keilmuan ini dapat diperoleh siapapun dengan syarat utama pembersihan jiwa (tazkiyatun Nafs), diikuti dengan mengamalkan pengetahuan yang telah dimilikinya.( Widho, Skripsi 2014). Secara umum, motif-motif batik yang diciptakan dengan latar belakang pemikiran dan tujuan tertentu mengandung nilai-nilai Islam.

Risalah Al Quran tidak hanya berisi aturan-aturan hidup saja, tetapi juga metode bagaimana menata dan mengorganisasikan kehidupan. Untuk itu, ayatayat Al Quran tidak hanya dipahami arti tekstualnya, tetapi juga harus dipelajari bagaimana metode enkulturasinya sebagai solusi masalah sosial di masyarakat. 
Proses dialektika Islam (Al Quran dan Hadis) dengan budaya lokal harus mengutamakan sikap toleran terhadap variasi yang bersifat partikuler. Kebudayaan suatu daerah harus menjadi medium bagi transformasi ajaran Islam. ${ }^{10}$ Tampaknya dialektika demikian yang disuguhkan dalam motif batik Surakarta. Nilai Islam yang terkandung dalam ayat-ayat Al Quran maupun hadis tentunya harus selalu melekat dan tercermin dalam penggunaan batik di masyarakat Surakarta. Ajaran Islam (Al Quran dan Hadis) yang berhubungan dengan budaya lokal ibarat pisau bermata dua. Sisi pertama Islam mengoreksi, memodernisasi, dan menjustifikasi keberadaan pranata-pranata lama. Tujuannya adalah untuk menjawab problem sosial budaya masyarakat saat itu sesuai dengan kebiasaan yang sudah ada. Sisi pertama ini bersifat partikular karena untuk kepentingan dan konteks tertentu. Sisi kedua, bahwa Al Quran dan Hadis meletakkan nilai-nilai baru yang universal dalam menyelesaikan persoalan umat manusia. Dalam konteks ini, nilai yang dienkulturasikan bersifat substansial, karena berupa prinsip dasar yang universal dan dapat diaplikasikan sepanjang masa. Prinsip dasar inilah yang harus selalu diterjemahkan, dirumuskan, dan diimplementasikan ke dalam system sosialbudaya masyarakat sekarang.

\section{F. Kesimpulan}

Sebagai daerah penghasil batik yang cukup terkenal, Surakarta berhasil memproduksi motif batik dengan sangat beragam. Motif-motif tersebut adalah Parang, Kawung, Sawat, Sidomukti, Truntum, Satrio Manah, Semen Rante, Wahyu Tumurun, Sekarjagat, dan Cuwiri. Masing-masing motif tersebut adalah simbolisasi yang menyimpan makna filosofis dari proses kehidupan manusia dalam konteks makrokosmos dan mikrokosmos. Adapun nilai-nilai Islam yang terekam dalam motif batik adalah berbagai macam perilaku dan peristiwa yang mengejawantahan ajaran Islam dalam sudut pandang aqidah, muamalah, dan akhlak. Semua motif batik selanjutnya memiliki spesialisasi untuk berbagai acara tertentu sejak manusia dalam masa kandungan, pernikahan hingga kematian.

${ }^{10}$ Ali Sadikin, Antropologi Al-Quran Model Dialektika Wahyu \& Budaya , h.209 


\section{DAFTAR PUSTAKA}

Anton Bakker dan Achmad Charris Zubair, Metode Penelitian Filsafat,Yogyakarta:Kanisius. 1990

Batik Solo dan Penjelasannya dalam www.batiktulis.com

Bogdan, R.C. \& Biklen S.K.Qualitative Research for Education : An Introduction to Theory and Methode. Boston : Allyn and Bacon, Inc. 1982

Budiono Herusatoto, Simbolisme Dalam Budaya Jawa, Yogyakarta: Hanindita Graha Widia, 2008

Darmokusumo, Murywati S., Batik Yogyakarta dan Perjalanannya Dari Masa Ke Masa, Jakarta:Kakilangit Kencana. 2015

Doellah, Santosa;Batik; Pengaruh Zaman dan Lingkungannya,Jakarta: Penerbit Gramedia. 2002

Endraswara, Suwardi, Filsafat Hidup Jawa, Yogyakarta:Penerbit Cakrawala, 2012

Frondizi, Risieri, Pengantar Filsafat Nilai, Penerbit Pustaka Pelajar, Yogyakarta. 2001

Hudaya, Achmad Sutrisno, Etika, Filsafat Praktis, Penerbit Ratuartha, Yogyakarta. 1980

Kaelan, Metode Penelitian Kualitatif Bidang Filsafat, Yogyakarta:Paradigma. 2006

Kusrianto, Adi, , Batik : Filosofi, Motif \& Kegunaan, Yogyakarta : C. V Andi Offset. 2013

Mashadi, Wisjnuwati dkk, , Batik Indonesia Mahakarya Penuh Pesona, Jakarta : Kakilangit Kencana. 2015

Miles dan Huberman. Penelitian Kualitatif dan Kuantitatif. Yogyakarta: Kanisius. 1984

Moleong, Lexy J., Metodologi Penelitian Kualitatif, cet ke. 20, Bandung: PT. Remaja Rosdakarya. 2004

Musman, Astin, dan Ambar B. Arini, Batik Warisan Adiluhung Nusantara. Jakarta:Penerbit G-Media. 2011

Sodiqin, Ali, Antropologi AL-Quran Model Dialektika Wahyu \& Budaya,Yogjakarta : Ar-Ruzz Media. 2008

Suseno, Franz Magnis, Etika Jawa, Jakarta: Penerbit Gramedia. 2001

Tibi, Bassam, Islam Kebudayaan dan Perubahan Sosial, Yogyakarta, Tiara Wacana. 1999

Van Zoest, Aart, Semiotika:Tentang Tanda, cara kerjanya dan Apa yang Kita LAkukan Dengannya,Jakarta:Yayasan Sumber Agung. 1993

Wahyu, Wawasan Ilmu Sosial Dasar, Surabaya: Usaha Nasional, 1986 